\title{
O DISCURSO BREVE DO PACIENTE: COMPREENDER E INTERPRETAR SEGUNDO WEIZSAECKER ${ }^{1}$
}

\author{
The Brief Discourse in the Clinic: to Understand and Interpret as Weizsaecker \\ El Discurso Breve del Paciente: Comprender e Interpretar Según Weizsaecker
}

JANE BorRaLHO GAMa

Francisco MarTins

\begin{abstract}
Resumo: Este trabalho tem por interesse compreender, na clínica, o processo metafórico presente no discurso dos pacientes. Para tanto, pesquisamos o discurso breve na clínica: compreender e interpretar segundo Weizsaecker adotando o método qualitativo: fenomenológico e hermenêutico. O objetivo é averiguar o sentir afetado do corpo próprio (Leib) da paciente L., que por meio do discurso reduzido breve, enunciados metafóricos, transporta sentido e mostra a sua intencionalidade para que seja interpretado e desvelado de modo a elevar à luz em reflexão, elaboração e ressignificação. Descrevemos uma série de enunciados metafóricos expressos por L., em dois anos de pesquisa, que trazem à luz as experiências vívidas registradas no corpo próprio (Leib) que expressam o sentir afetado em sofrimento. Para interpretação do discurso breve da paciente fundamentamos nosso estudo no ciclo da estrutura do teórico Weizsaecker. O ciclo da estrutura dos verbos páthicos: querer, poder, dever, dever moral e poder moral estão contidos nos discursos dos pacientes, portanto, nas experiências concretas, da realidade cotidiana. Os verbos páthicos são disposições particulares para o automover-se e o mover-se e estão em uma relação de referência à particularidade do ser.
\end{abstract}

Palavras-chave: Clínica; Discurso breve; Sentir afetado; Corpo próprio (Leib); Verbos páthicos.

\begin{abstract}
This work aims to understand in clinic the metaphorical process present in the patient's discourse. To do so, we researched the brief discourse in the clinic: to understand and interpret as per Weizsaecker. In this work we adopted a qualitative method: phenomenological and hermeneutical. The goal of this research is to assess the affected feeling in the very body (Leib) of patient L. by means of brief reduced discourse and metaphorical statements that convey meaning and show the intentionality of the patient, so they can be interpreted and unveiled so as to shed light on them in reflection, elaboration and resignification. We described a series of metaphorical statements uttered by L., in two years of research, which bring to light the vivid experiences registered in the very body (Leib) that express the affected feeling in suffering. For interpreting the patient's brief discourse we took basis on Weizsaecker's structure cycle. The structure cycle of pathos verbs-want, can, must, should, and mayare contained in the patients' discourses; therefore, in the concrete experiences of everyday life. The pathos verbs are particular dispositions for the self-moving and the moving and are in a relation of reference to the particularity of being.
\end{abstract}

Keywords: Clinic; Brief discourse; Affected feeling; Very body (Leib); Pathos verbs.

Resumen: Este trabajo pretende comprender, en la clínica, el proceso metafórico presente en el discurso de los pacientes. Para ello, investigamos el discurso breve en la clínica: comprender e interpretar según Weizsaecker adoptando el método cualitativo (fenomenológico y hermenéutico). El objetivo es averiguar el sentir afectado del cuerpo propio (Leib) de la paciente L., que mediante el discurso reducido breve y enunciados metafóricos transporta sentido y muestra su intencionalidad, para que sea interpretado y desvelado y salga a la luz para reflexión, elaboración y resignificación. Describimos una serie de enunciados metafóricos expresados por L. a lo largo de dos años de investigación, que sacan a la luz las experiencias vívidas registradas en el cuerpo propio (Leib) que expresan el sentir afectado por el sufrimiento. Para interpretar el discurso breve de la paciente nuestro estudio se basa en el ciclo de la estructura del teórico Weizsaecker. El ciclo de la estructura de los verbos páthicos: querer, poder, deber, deber moral y poder moral están en el discurso de los pacientes y, por ende, en las experiencias concretas de la realidad cotidiana. Los verbos páthicos son disposiciones particulares para el automoverse y el moverse y se encuentran en una relación de referencia a la particularidad del ser.

Palabras-clave: Clínica; Discurso breve; Sentir afectado; Cuerpo propio (Leib); Verbos páthicos.

\section{Introdução}

Temos por interesse, neste trabalho, compreender, na clínica, o processo metafórico presente no discurso

\footnotetext{
Este trabalho é derivado de dissertação intitulada: "A metáfora do caminho: uma investigação fenomenológica existencial na clínica”, dezembro de 2010. Aprovada pelo Comitê de Ética e Pesquisa do Instituto de Ciências Humanas da Universidade de Brasília.
}

dos pacientes. O objetivo é averiguar o sentir afetado, do corpo próprio (Leib) da paciente L. que por meio do discurso reduzido breve, enunciados metafóricos, transporta sentido e mostra a intencionalidade da paciente, para que seja interpretado e desvelado de modo a refletir, elaborar e ressignificar.

Descrevemos uma série de enunciados metafóricos expressos por L., registrados por anotações, em dois anos 
de pesquisa, durante as sessões psicoterapêuticas e que trazem à luz as experiências vívidas registradas no corpo próprio (Leib) que expressam o sentir afetado em sofrimento. Como método nesta pesquisa, utilizamos o método fenomenológico e hermenêutico. E formalizamos o embasamento teórico nos fundamentos do filósofo Paul Ricoeur que desenvolve na Metáfora Viva, a compreensão da metáfora para além da retórica, descrevendo o valor da significação na semântica da frase que define como discurso breve reduzido ou enunciado metafórico. Para análise interpretativa dos enunciados metafóricos, enunciados pela paciente L., nos apoiamos nas categorias dos verbos páthicos no Ciclo da Estrutura de Viktor von Weizsaecker.

A experiência vívida é compreendida como a intensidade expressiva da experiência vivida que se faz presente no ato do enunciado. O termo sentir afetado é proposto como as qualidades sentidas sobre as coisas ou pessoas que revelam o modo como o eu se vê intimamente afetado no momento da enunciação. Tal compreensão está fundamentada no que Ricoeur define como sentimento, "nada mais nada menos que a direção mesma do comportamento enquanto sentido" (Ricoeur, 2009a, pp. 293294). O corpo próprio (Leib) é compreendido como o corpo físico (Körper), que tendo corporificado a experiência vivida, registra em si os afetos sentidos.

\section{O Discurso Breve Reduzido e a Significação em Paul Ricoeur}

Paul Ricoeur (1913 - 2005), filósofo francês, introduziu Husserl na França com Levinas e Merleau-Ponty. Ricoeur considerado como um dos mais importantes filósofos da segunda metade do século XX estabeleceu uma ligação entre a fenomenologia e a análise da linguagem em que desenvolve na Metáfora Viva (1975), um segmento da metáfora que tem início na retórica clássica, passando pela semiótica e pela semântica, para alcançar finalmente a hermenêutica. Em seguida, publica a Teoria da Interpretação: O Discurso e o Excesso de Sentido (1976) que também é inserido no horizonte das investigações a propósito da linguagem e do discurso. Essas duas obras que antecedem a trilogia Tempo e Narrativa (1983, 1984 e 1991) são fundamentais para este estudo. Ricoeur admite a metáfora não mais como palavra, mas na semântica da frase em que define como discurso breve reduzido ou enunciado metafórico.

Indaga o filósofo: "Se a metáfora consiste em falar de uma coisa nos termos de outra, não consistirá também em perceber, pensar ou sentir, a propósito de uma coisa, nos termos de outra?" (Ricoeur, 2005, p. 134). Esta indagação nos leva a investigar a importância, na clínica, dos enunciados metafóricos proferidos pelos pacientes, pois por ausência de significação o paciente é acometido por sentimentos aflitos.
Segundo Ricoeur os enunciados metafóricos "são constituídos em discursos breves reduzidos, o mais das vezes, a uma frase" (Ricoeur, 2005, p. 371). Os enunciados metafóricos são reconhecidos na interpretação semântica, visto que para o autor " $a$ frase é definida como primeira unidade portadora de significação do discurso." (Ricoeur, 2005, p. 77). Os enunciados metafóricos são fenômenos de linguagem que transportam sentido possibilitando a significação por meio da interpretação.

Temos como hipótese a premissa de que o sentido como significação, do sentir afetado, do corpo próprio (Leib), é transportado por enunciados metafóricos. Os enunciados metafóricos constituem fenômeno da linguagem e expressam a experiência vívida do sentir do corpo próprio (Leib) afetado que na clínica são expressos, predominantemente, por dor e sofrimento.

A metáfora, para Ricoeur, não existe em si mesma, mas numa e por uma interpretação. É o conflito entre duas interpretações, uma literal e outra metafórica, ao nível de toda a frase que sustenta a metáfora, extraindo uma verdadeira criação de sentido, uma vez que a interpretação literal seria absurda. Define o autor: "A metáfora se assemelha mais à resolução de um enigma do que a uma associação simples baseada na semelhança; é constituída pela resolução de uma dissonância semântica, resultando da tensão entre dois termos, cuja significação é resultante de sua interação" (Ricoeur, 2009b, p. 76).

Ricoeur diferencia as metáforas mortas e as metáforas vivas. As metáforas mortas são as que já não são metáforas, expressões como "o pé da cadeira”. As metáforas vivas são metáforas de invenção criativa. Emerge na metáfora viva uma nova significação que engloba toda a frase. Para ele é "só no nível da frase que nos é permitido distinguir o que é dito e aquilo acerca de que se diz" e que constitui uma intenção do sujeito lógico do discurso, o referir-se a si mesmo (Ricoeur, 2009b, p. 35). Afirma Ricoeur, "é na metáfora viva que se tem um valor emotivo por oferecer uma nova informação, ou seja, dizer algo acerca da realidade" (Ricoeur, 2009b, p. 77). Na clínica, a realidade a que o paciente se refere é ao eu, de modo a desvelar o quantum do sentir afetado refletido do corpo próprio (Leib).

Por meio da interpretação, é possível ser desvelada a intencionalidade do paciente. $\mathrm{O}$ paciente partilha as experiências vividas pelo ato da fala que abrange além do dizer, as expressões fisionômicas, os gestos, as emoções valoradas pela intensidade e tonalidade da voz. Estes fenômenos fundamentam, pois, no contexto presente do paciente, a intencionalidade do paciente em dar significação para que possa apropriar-se por meio da compreensão interpretativa de um novo sentido, de modo a reorientar-se no caminho da vida.

A interpretação dos enunciados metafóricos expressos pelos pacientes possibilita, a nós clínicos, compreender o modo que o paciente estrutura o seu sistema de conceitos e que governam o pensar, o sentir e o mover-se. Ao partilhar a experiência vivida, o paciente evoca percepções 
antigas, ou seja, recordações. De maneira que, ao recordar, o paciente revive uma percepção, uma sensação, remontando o passado que reativa na memória. Para Ricoeur, "a comunicação de uma experiência vivida, como vivida, permanece privada, mas o seu sentido, a sua significação, torna-se pública. A comunicação é, desse modo, a superação radical da não comunicabilidade da experiência vivida enquanto vivida" (Ricoeur, 2009b, p. 30). O paciente torna público ao compartilhar com o terapeuta dos seus segredos, da sua história, dos seus sonhos de modo a dar significação à experiência vivida.

Esta experiência uma vez reativada mostra por meio dos enunciados, das emoções suscitadas, das expressões do corpo, o quantum dos afetos constelados, vivificandoos e mostrando o caminho para o qual tende o automover-se e o mover-se do paciente.

O automover-se é compreendido na concepção biológica que não é um segmento de causa e efeitos é um acontecimento espontâneo. E o mover-se coincide com a gênese da forma que dependem, todas às vezes, dos estímulos exteriores e da intencionalidade própria. Essas compreensões encontramos no Ciclo da Estrutura em Weizsaecker.

\section{O Ser Páthico no Caminho da Vontade e da Graça em Weizsaecker}

Viktor Von Weizsaecker (1886 - 1957), médico e filósofo alemão, é precursor da medicina antropológica e da medicina psicossomática. Em Heidelberg foi consagrado pelo estudo da neurologia clínica e da neurofisiologia. Recebeu influências da fenomenologia de Husserl de modo relevante que se faz presente nas suas obras, dentre elas a obra escrita em 1940, denominada Der Gestalkreis, com tradução para o francês Le cycle de la structure. Weizsaecker nesta obra nos mostra que o ciclo da estrutura da existência se renova e se reflete sobre ela mesma a cada apreensão recíproca do sujeito com o seu mundo. Para Weizsaecker, "o mais profundo da existência humana é a passagem do ser para o devenir" (Weizsaecker, 1958, p. 11).

Para Weizsaecker a estrutura da crise se estabelece na dialética da liberdade e da necessidade de maneira que o conflito cíclico, em termos subjetivos, se estabelece entre o querer e o dever. Para o autor, o páthico pode se definir como a origem do querer e do dever. "Ele é sempre a origem dos quereres e dos deveres particulares" (Weizsaecker, 1958, p. 220).

As categorias páthicas descritas por Weizsaecker se configuram em cinco verbos. São verbos páthicos: querer no sentido da vontade, desejo (Wollen); dever como necessidade, precisar (Müssen); poder no sentido de ser capaz, entender (Können); o dever moral no sentido de ser obrigado (Sollen) e o poder moral (Dürfen) de ter permissão, autorização, ter o direito. Estes verbos, para Weizsaecker, são páthicos porque estão em uma relação de referência à particularidade do ser.
De acordo com o ciclo da estrutura definido por Weizsaecker há dois modos condicionais de caminho: o da vontade, na qual o homem tem a liberdade para escolha e o da graça, caminho em que há uma intencionalidade da vida que o homem não controla.

No caminho da vontade há um querer, uma vontade em uma disposição páthica do automover-se para o mover-se. Há uma preponderância do querer sobre o poder, a sentença se enuncia: "Tu podes, se tu queres" (Weizsaecker, 1958, p. 221). Ou seja, a vontade, o querer se efetua concretamente. No entanto, há na existência condições que se interpõem independentes do querer o que faz prevalecer o verbo páthico do poder.

Para Weizsaecker, quando o poder se sobrepõe à vontade, ao querer, o caminho se constitui no caminho da graça, pois o mover-se se dá na condição de que seja concedido o poder para o querer. A sentença se enuncia: “Tu quererás, se a ti é dado o poder" (Weizsaecker, 1958, p. 221). Há uma condição de que seja dado o poder para que o querer advir. No ciclo da estrutura no caminho da vontade é necessário que o querer determine a ação para o automover-se e que seja dado o poder para que seja consumado o querer em um mover-se.

No caminho da vontade há um querer, uma vontade em uma disposição páthica do automover-se para o mover-se. É importante ter a vontade, o querer para o automover-se, que é gerado a partir de uma disposição particular para fazer ação em um mover-se. No caminho da graça é necessário que seja concedido o poder para que a vontade seja consumada. Vejamos os enunciados da paciente L. que desvelam o sentir afetado do corpo próprio (Leib) em sofrimento. Para tanto, analisamos de modo interpretativo baseado nos filósofos: Paul Ricoeur na compreensão do discurso breve, ou enunciados metafóricos e dos verbos páthicos de Viktor von Weizsaecker.

\section{O Discurso Breve com Base nas Experiências Ví- vidas do Corpo Próprio (Leib) da Paciente L.}

A paciente L. é uma mulher de 45 anos, dedicada ao trabalho em uma exigência para consigo mesma de perfeição, de dever como obrigatoriedade, como ordem a ser cumprida. No enunciado metafórico L. diz:

“(...) Eu sinto como se tivesse recebido uma facada no peito.”

L. diz do seu sofrimento, de algo que está ferido, em um sentir que sangra. O pronome "Eu" referencia a si mesma no modo de se sentir no mundo, ferida.

Enuncia L.:

“(...) Eu estou apática. De dez anos para cá eu me tornei diferente. Estou mal cuidada, perdi a minha espirituosidade. Eu era mais alegre." 
L. expressa em um lamento presente em algo perdido no passado. Este algo perdido se inscreve na experiência vivida do corpo próprio (Leib). L. diz ter se tornado diferente. O tornar-se para L. é transfiguração da aparência no abandono do corpo, "estou mal cuidada", na mudança no humor "perdi a minha espiritualidade", da alegria para o estado de apatia. L. está apática, ou seja, sem ânimo, sem direção e sentido. Há impedimentos. Há angústia. O desejo de L. é de algo que se perdeu no passado e que está requerendo por ter perdido. As experimentações da vida tornam-se densas, enfadonhas, o que a leva ao abandono de si mesma, com sensações de um corpo próprio (Leib) disforme.

L. versa entre as sensações do corpo próprio (Leib) da plenitude para o esvaziamento, do admirável para o desprezível, da alegria para o apático. Da experiência à conceituação da vida, da experimentação da vida como espiritualidade para um sentimento afetado, que a tem deixado em um estado de desinteresse para consigo, em estado alterado do humor, apático, comprometendo a sua disposição para o automover-se. L. enuncia:

\section{“(...) Eu só vivo de passado, eu não tenho futuro, nem presente."}

L., ao dizer viver de passado, reafirma o seu mover-se em uma direção e sentido às reminiscências. Fixada em acontecimentos passados, os desejos se perdem em um lamento. L. retém na memória recordações passadas que a aprisionam, de modo a mover-se em um ir e vir sob o dever como obrigatoriedade. No enunciado metafórico L. diz:

\section{“(...) A sensação que tenho é de estar carregando cadáveres."}

A sensação como experimentação sensorial no corpo próprio (Leib) em um mover-se que traz consigo carga, peso, cadáveres. Este mesmo enunciado metafórico após alguns meses de trabalho é novamente expresso:

\section{“(...) Tenho a sensação de estar carregando cadáveres.”}

L. dá a seguinte significação para o que sejam cadáveres:

“(...) Cadáveres podem ser uma coisa, podem ser um peso morto, uma pessoa, uma situação, um fato que aconteceu” e complementa: “(...) 'Eu tenho que' me livrar destes cadáveres, me livrar desses pesos mortos. Preciso me livrar. Vejo que estão em uma fase terminal e não os deixo morrer. Preciso extirpar uma coisa que eu não quero na minha vida."

Comprovamos nesta experiência clínica a importância da significação do enunciado pelo paciente, no momento em que enuncia. Visto que pudemos confirmar que o enunciado foi vivificado, de modo a produzir em L. re- flexões para elaboração só depois de ter significado o que são os cadáveres. As imposições morais do dever em L. a distanciam do seu sentir fundamental, comprometendo a sua disposição pulsional para realização do querer que são traduzidos pelos sintomas simbólicos marcadas no corpo (Körper), como problemas endocrinológicos, que pouco a pouco tomam significação.

O domínio do dever moral, como obrigação "a ter que" produz em L. um dano, um prejuízo existencial, pois fere a sua condição ética de estar no mundo, de modo a defender a si mesma face ao dever como necessidade em uma disposição à sua vontade. L. se refere ao eu no mover-se de um corpo próprio (Leib) que carrega cadáveres, ainda que, em fase terminal, não se desfaz do peso morto. Sustentada nas experiências vividas, L. está em apego, pois não deixa de olhar para o passado que a petrifica. $\mathrm{O}$ seu sentir afetado é reafirmado a cada sessão em lamento, em choro, em sofrimento.

Para Ricoeur (2009a), o sentimento visa qualidades sentidas sobre as coisas ou sobre as pessoas e ao mesmo tempo desvela o eu no sentir afetado. $\mathrm{O}$ afeto é o modo como o corpo (Körper) experimenta quando afetado. L. está afetada e expressa a experiência vivida, na qual o sentimento manifesto pelo sofrimento aflitivo, pela inquietude do corpo (Körper), dá a direção e o sentido para o qual tende o mover-se. O mover-se de L. está automatizado em um esforço posto ao dever como obrigação. Há um impedimento que gera angústia e que interfere no devenir. L. tem medo de sentir o que sente. Pelo medo, L, distancia-se do sentir de modo a mover-se tendendo à direção para um estado de depressão ansiosa. É no partilhar da experiência vivida do corpo próprio (Leib) que o paciente, por meio da fala, diz acerca do seu sentir no modo em que o eu se encontra afetado.

L., ao enunciar: "(...) Preciso me livrar." "Preciso extirpar uma coisa que eu não quero na minha vida" começa a dar os primeiros passos, sinalizando um querer, um dever, uma necessidade. Este precisar é base fundamental para que "se deva", ou seja, para que haja uma necessidade, na particularidade do ser. Para tanto é necessário que L. extirpe o que não quer na sua vida. Neste enunciado metafórico, L. diz em um apontar direcionado ao querer, pois precisa, necessita, deve livrar-se de algo, extirpar uma coisa e que a coloque em um estado de liberdade.

A necessidade como um dever para consigo mesmo dá uma nova direção e sentido, apontando para um querer. L. começa a valorar entre o querer e o não querer. Há uma luta em L. para que não seja dominada, tomada por afetos. O esforço far-se-á no sentido de livrar-se desses pesos mortos que afetam o seu modo de viver. Ao se constituir no querer, L. tenderá a uma nova direção e sentido que a fará tomar decisões consubstanciadas em um viver, realizando a si mesma, sem que tenha que sofrer para existir ou, mesmo, "carregar cadáveres".

O sentir afetado de L. a leva às reminiscências infantis. L. enuncia: 
“(...) Eu me sinto como se fosse uma menina de 10 anos de idade. Pensei que quando chegasse aos 45 anos eu já fosse uma mulher e, diante do meu pai, eu me sinto uma menina de 10 anos."

Este enunciado é significativo para o trabalho clínico, pois trata das questões do complexo edípico. L., ao partilhar a experiência vivida marcada no corpo próprio (Leib), dá abertura para que pouco a pouco tratemos deste núcleo que afeta a todos nós, as relações afetivas com as figuras parentais. L., ainda aos 45 anos, se sente menina diante da autoridade do pai. L. está em estado regredido, sob o domínio do amor filial. L. está ressentida. O ressentido sofre de uma memória reiterada, de um impedimento de esquecer que faz com que L. ab-reaja em choro ao tratar da sua relação com a figura paterna durante dois anos de trabalho.

Para Nietzsche "cada um que sofre procura instintivamente a causa da sua dor, e procura uma causa animada, uma causa responsável, suscetível de sofrer, um ser vivo contra o qual possa, ao menos em efígie, descarregar a sua paixão" (Nietzsche, 2009, p. 122). Para ele, esta vingança é o supremo alívio, o narcótico de todos os que sofrem. $\mathrm{O}$ que L. resiste em esquecer? O poder da autoridade se sobrepõe ao querer que a faz permanecer no passado, sem futuro e sem o fluir da vida que se faz presente no devenir. Há um ressentimento que faz com que L. esteja presa ao passado. L. deseja algo que não se cumpriu e, fixada, busca de modo incansável que se cumpra em meio ao ideal de sentir o amor, o cuidado do pai. L. vive em nostalgia, em tempos passados e reconhece o seu sofrimento, mas atribui o seu sofrimento à responsabilidade de "um outro", suposto agente do mal que a vitimou.

L. está destituída da vontade para automover-se que com frequência enuncia o sentimento de um esforço fracassado. Está mortificada, em negação e sacrifício de si mesma. Enuncia L.:

“(...) Para mim é como se eu tivesse subido, subido, subido e cheguei lá em cima do morro e agora estou na sacada da casa, parada."

O modo de sentir ao qual L. se refere é um moverse sem direção e sentido, com o corpo próprio (Leib) em exaustão. O conceito ao qual L. está estruturada é a vida como esforço. O mover-se de L. faz-se pelo dever, como obrigação, como condição moral a ser obrigado a algo externo ao querer, à vontade. É, portanto, no sentido de obrigatoriedade que se confirma, mais uma vez, por meio dos enunciados metafóricos que se dá o mover-se de L..

O dever moral se sobrepõe sobre o querer que a estrutura em uma forma de pensar e agir por vezes com certa rigidez. Para L., "é como se" em uma estrutura imaginária de uma condição comparativa de estar no mundo, de sentir-se em um mover-se em ação de subir com esforço. Ao dizer "estou na sacada da casa, parada", o estar parada poderia ser compreendido como contemplação por ter alcançado um objetivo existencial depois do esforço. No entanto, a significação do "estar parada" diz de uma imobilidade, de um vazio, de uma impossibilidade em dar seguimento no caminho da existência por não saber a direção e o sentido para o qual a sua vontade, o seu querer a determinaria para mover-se que pôde ser valorado pelo tom e intensidade da voz.

No enunciado metafórico, L. diz:

“(...) Eu tinha tudo para naufragar, cair do barco e morrer. Eu me salvei porque eu me diferenciei."

Este enunciado remete a uma alegoria na produção da imagem fundada no que representa à navegação. $\mathrm{O}$ simbolizante barco é simbolizado como instrumento de navegação, de conquista de terras distantes, de realização do percurso do destino por vias fluviais, mas também de naufrágio como impedimento para travessias. Naufragar significa sofrer naufrágio, perder-se, extinguir-se, malograr-se, fracassar, perder uma embarcação em virtude de um acidente marítimo, afogar. No naufrágio o sentido de descida é de afundar, de morrer por afogamento, sufocação. Há neste enunciado uma paisagem que reflete a imagem produzida em que L., sendo o barco, tinha tudo para naufragar, se afogar, sufocar e estando no barco, tinha tudo para cair e morrer em queda. Mas L. se diferencia, o que a salva. O diferenciar-se para L. está na força com que L. embate para o mover-se em um dever de ter que, como necessidade, para manter-se em navegação que nos mostra que há em L., uma intenção de um querer para automover-se em direção e sentido de modo a dar significação à existência.

Diz o enunciado metafórico de L.:

\section{“(...) A vida é uma selva de pedra - tem sido uma luta.”}

O caminho da vida para L é de luta, de coisas selvagens, habitado por um núcleo duro, de pedra. L. é sensível ao mundo e inquieta-se em uma busca permanente em compreender o que se instala de modo selvagem no seu corpo próprio (Leib) e que a leva a mover-se em um ir e vir, subir e descer, naufragar e sobreviver.

O mover-se de L. está automatizado em um esforço posto ao dever como obrigação. Há um impedimento em L. que interfere no seu devir e que gera angústia, mas que L. tem medo de sentir as sensações que dela advém. Pelo medo, L, distancia-se do sentir de modo a mover-se tendendo a direção de um estado de depressão com ansiedade. L. Enuncia:

\section{“(...) Eu tenho que estar cheia de coisas senão eu entro no vazio."}

L. enche-se de "coisas", em um fazer compulsivo, para distanciar-se e assim não sentir o vazio, a estranheza. $O$ vazio é assustador e por medo, distancia-se do sentir fundamental, o que faz sobrepor o ter sobre o ser. O que era "ser" passa a se constituir no "ter".

Nesse momento, o desejo está em buscar veementemente o objeto fora de si mesmo. Esta busca provoca consequentemente um estado de inquietação, de perturbação aflitiva 
com modos de afetação com relação ao eu, de susto e medo. L. tem medo de sentir o que sente tendendo a mover-se em aflição, mostrando-se e escondendo-se do seu verdadeiro sentir na busca ansiosa por algo perdido. Assim, L. distancia-se do pensar a vida, do silêncio, de modo a poder encontrar em si sentido que dê significação ao existir.

Entretanto, ao sair da sessão, por um momento, enuncia o seu refletir acerca da vida:

\section{“(...) Nós só buscamos porque temos certeza do fim.”}

L. mostra o seu pensar a existência. L. mostra a sua sensibilidade, mas encontra-se consumida por um eu em desespero, refugiando-se no medo de sentir o que sente e colocarse em abertura para poder refletir a vida. L. tem potencial criativo para pensar em profundidade a vida, mas resiste a lançar-se a esta possibilidade como meta a ser cumprida.

\section{Considerações Finais}

O trabalho embasado na filosofia de Paul Ricoeur no que se refere ao discurso breve reduzido ou enunciados metafóricos e nas categorias páthicas configuradas na significação dos verbos querer, dever, poder, dever moral e poder moral de Viktor von Weizsaecker, bem como em uma metodologia científica para a Pesquisa Clínica, método qualitativo, resultou em observações a serem consideradas, de modo a consolidar e contribuir no trabalho clínico.

Evidenciamos que os enunciados metafóricos estruturam conceitos que levam à compreensão da experiência vívida, do sentir afetado do corpo próprio (Leib) do paciente. Há uma intenção do paciente em partilhar a experiência vivida para dar maior clareza ao seu pensar, ao seu sentir, ao seu mover-se desvelando verdades ao serem interpretadas.

Podemos constatar que os enunciados metafóricos expressos por L. são originários das experiências concretas, da realidade da sua vida cotidiana e que foram formulados em base às experiências vividas. A referência à qual a paciente alude é ao eu, no que diz respeito ao seu modo de estar no mundo, mostrando por meio das suas emoções, no mover das paixões, o quantum dos estados afetivos que, constelados, impedem ou mesmo são propulsores para o mover-se.

O conceito que estrutura o modo de ser de L, no qual experiencia a vida, é de sofrimento. L. mantém-se soerguida na vida com esforço, com dificuldade, em um sentir do corpo próprio (Leib) carregado de afetos.

O investimento pulsional de L. está no devea para, como condição moral a ser obrigado a algo externo ao seu querer, à sua vontade. $\mathrm{O}$ modo na qual L. está estruturada, de acordo com as disposições páthicas de Weizscaecker, que a faz compreender o mundo e a si mesma é do dever moral sobreposto ao querer. O dever moral é o dever em que se está em obrigação a. Esta compreensão, portanto, reflete na expressão de um corpo próprio (Leib) em exaustão, em saturação.
O fenômeno que se mostra por meio do discurso breve em intensidade valorado pelo tom de sua voz, pelas expressões gestuais é de que L. está afetada por ressentimento que a faz mover-se na direção e sentido fixado no passado na tentativa de fazer cumprir o que para ela foi perdido. É necessário que L. chegue à compreensão da sua sensibilidade do pensar a mais a vida e, assim, perceba a profundidade do ser que é.

No enunciado metafórico o paciente diz, comunica, partilha a experiência vivida. A pesquisa demonstra a força intencional do eu para lidar racionalmente com o que sente, diante do inominável. O paciente tenta dar significação ao sentir utilizando como recurso o discurso breve reduzido ou enunciados metafóricos. Deste modo, os enunciados metafóricos contribuem para dar clareza à experiência vívida do corpo próprio (Leib) padecido em dor e sofrimento pela ausência de significação.

Podemos concluir que há uma intencionalidade do paciente em dar significação aos afetos em que o corpo próprio (Leib) está tomado, possibilitando, assim, reflexão, elaboração e ressignificação.

O paciente, ao partilhar a experiência vívida, diz de modo a superar a solidão da vida, iluminada por um momento pela luz do discurso. Como afirma Ricoeur: "Eis o milagre!” (Ricoeur, 2009b, p. 34).

\section{Referências}

Nietzsche, F. (2009). A genealogia da moral. Petrópolis: Vozes.

Ricoeur, P. (2005). Metáfora viva. São Paulo: Edições Loyola.

Ricoeur, P. (2009a). Na escola da fenomenlogia. Petrópolis: Vozes.

Ricoeur, P. (2009b). Teoria da interpretação: o discurso e o excesso de significação. Lisboa: Edições 70.

Weizsaecker, V. V. (1958). Le cycle de la structure. Paris: Desclée de Brouwer.

Jane Borralho Gama - Psicóloga Clínica. Mestrado e Doutoranda em Psicologia Clínica e Cultura na Universidade de Brasília (UnB). Endereço para correspondência: SCN Q. 05 Torre Sul Sala 210 Centro Empresarial Brasília Shopping. Brasília - DF. 70.715-900. E-mail: janeborralho@globo.com

Francisco Martins - Professor Titular na Universidade de Brasília, Psiquiatra, Psicólogo, Psicanalista. Endereço Institucional: UnB/ Campus Universitário Darcy Ribeiro/ICC - Ala Sul - Instituto de Psicologia, Departamento de Psicologia Clínica (Asa Norte). CEP 70919-990 - Brasília/DF. E-mail: fmartins@unb.br.

Recebido em 13.08.11

Primeira Decisão Editorial em 10.11.11

Aprovado em 30.12.11 